UC3M Working Papers

Business

17-01

ISSN 2387-175X

May 2017
Departamento de Economía de la Empresa Universidad Carlos III de Madrid Calle Madrid, 126 28903 Getafe (Spain) Fax (34-91) 6249607

\title{
The Effect of Patent Protection on Inventor Mobility
}

Eduardo Melero*

Neus Palomeras

David Wehrheim

Department of Business Administration, Universidad Carlos III de Madrid

\begin{abstract}
This paper investigates the effect of obtaining a patent on the mobility of employee inventors who are at the beginning of their careers. We suggest that patents make human capital more specific to the employer. As a result, we expect that patenting leads to lower levels of mobility. We draw on U.S. patent application data for the period 2001-2012 to analyze this issue. Using average examiner leniency as an exogenous source of variation in granted patents, we find that one additional patent granted decreases inventor mobility by approximately 25 percent. The estimated negative effect is nearly twice as large for discrete technologies (chemicals and pharmaceuticals) for which patent effectiveness is greater. The effect is also more pronounced in cases where the inventor's knowledge can be independently transferred (e.g., inventors with few co-authors) and for moves concerning technologically similar employers. The results have implications for the effect of patents on knowledge diffusion.
\end{abstract}

Keywords: Inventors, Patents, Mobility, Appropriation, Firm-specific Human Capital JEL classification: J62, O32, O43

\footnotetext{
*Corresponding autor. Email: eduardo.melero@uc3m.es.
} 


\title{
The Effect of Patent Protection on Inventor Mobility*
}

\author{
Eduardo Melero $^{\dagger}$, Neus Palomeras ${ }^{\ddagger}$ and David Wehrheim ${ }^{\S}$ \\ Department of Business Administration, Universidad Carlos III de Madrid, Spain
}

\begin{abstract}
This paper investigates the effect of obtaining a patent on the mobility of employee inventors who are at the beginning of their careers. We suggest that patents make human capital more specific to the employer. As a result, we expect that patenting leads to lower levels of mobility. We draw on U.S. patent application data for the period 2001-2012 to analyze this issue. Using average examiner leniency as an exogenous source of variation in granted patents, we find that one additional patent granted decreases inventor mobility by approximately 25 percent. The estimated negative effect is nearly twice as large for discrete technologies (chemicals and pharmaceuticals) for which patent effectiveness is greater. The effect is also more pronounced in cases where the inventor's knowledge can be independently transferred (e.g., inventors with few co-authors) and for moves concerning technologically similar employers. The results have implications for the effect of patents on knowledge diffusion.
\end{abstract}

KEYWORDS: inventors, patents, mobility, appropriation, firm-specific human capital

JEL Classification: J62, O32, O43

\footnotetext{
${ }^{*}$ We are grateful to Emre Ekinci, Peter Mueser, Natalia Zinovyeva, and seminar participants at Universidad Carlos III de Madrid and TECHNIS for their suggestions on early versions of this paper. All errors are our own.

${ }^{\dagger}$ Correspondence to Eduardo Melero, Department of Business Administration, Universidad Carlos III de Madrid, Calle Madrid 126, 28903 Getafe (Madrid), Spain; E-Mail: eduardo.melero@uc3m.es.

${ }^{\ddagger}$ E-Mail: neus.palomeras@uc3m.es.

${ }^{\S}$ E-Mail: davidalexander.wehrheim@uc3m.es.
} 


\section{Introduction}

The patent system is a major instrument for articulating government innovation policy. Patent rights are expected to provide incentives for innovation and to foster the diffusion of knowledge. Economists, legal scholars and policy advisors, however, have long questioned the effectiveness and efficiency of the patent system in reaching these goals (see, e.g., Federal Trade Commission, 2003). First, awarding monopoly rights as a reward for innovation involves the obvious deadweight loss and rent-seeking costs associated with monopolies (Nordhaus, 1969; Boldrin and Levine, 2013). Furthermore, it is unclear whether patents help or hinder the diffusion of knowledge and, ultimately, the generation of further innovation. On the one hand, historical evidence shows that the use of patent protection encouraged the geographical diffusion of innovations in the chemical industry (Moser, 2011) and the exchange of ideas in markets for technology (Lamoreaux and Sokoloff, 1999). On the other hand, increased fragmentation of ownership rights among firms, combined with the recombinant nature of new knowledge, may lead to steep increases in the transaction costs associated with transferring patent-protected knowledge (Heller and Eisenberg, 1998), thus hampering its diffusion. Recent research on the impact of patents on subsequent innovation is also inconclusive. While Galasso and Schankerman (2015) provide evidence of substantial increases in citations of patents that are invalidated by courts, Sampat and Williams (2015) show that patents on genes do not hinder subsequent related innovations.

Complementing this debate on patents and the diffusion of knowledge, this article studies an indirect, albeit important, mechanism through which patents may affect the circulation of knowledge: inventor mobility. Since Arrow (1962, p. 615) noted that "mobility of personnel among firms provides a way of spreading information," economists have identified labor mobility as a key conduit through which knowledge spillovers occur. In this respect, the mobility of the R\&D personnel responsible for technological advances is particularly relevant. Previous research has documented the inter-firm transfer of technical knowledge following inventor moves (Almeida and Kogut, 1999; Maliranta et al., 2009; Singh and Agrawal, 2011). Therefore, understanding the causal relationship between patent protection and inventor mobility will allow us to have a more complete picture of the role of patents in the diffusion of knowledge.

We explicitly explore the effect of patenting on the career moves of the inventors responsible for the underlying innovations. Following the existing literature on intellectual property (IP) rights, we hypothesize a negative effect of patents on inventor mobility. Patents grant their owners (usually the employer of the inventor) a time-limited right to prevent others from using a given technology. Consequently, they restrict the amount of knowledge that an inventor can effectively use following a move to a new employer (Kim and Marschke, 2005; Agarwal et al., 2009). Furthermore, by conferring monopoly power over a given technology, patent rights increase the value of retaining the creators of that technology in the implementation phase. This makes the human capital of inventors with (issued) patents more specific to their current employers and makes them less likely to move.

Testing the aforementioned hypothesis poses an important methodological challenge. Since patented innovations are inherently different from non-patented ones (as their inventors are also likely to be), a simple comparison of inventors who patent with those who do not might lead to 
conclusions that only mirror the underlying dissimilarities. First, the firm decision to apply for patent protection depends on the characteristics of the given innovation (see Criscuolo et al., 2015), which may also reflect certain attributes of the human capital of its inventor(s). Second, the decision to apply for a patent is likely to be affected by the dynamism of the inventor labor market, as suggested by Kim and Marschke (2005). Moreover, the applications that are finally granted patents are a selected group of innovations, namely, those that imply sufficient advancement in the state of the art according to the patent office requirements (i.e., novelty and non-obviousness of the inventive step). These requirements are arguably more likely to be achieved by talented inventors. Hence, a straightforward comparison between patented and non-patented innovations is not appropriate.

We investigate the effect of patenting on inventor mobility by comparing the trajectories of inventors with different numbers of issued patent (among those with a given number of applications filed). In order to estimate the causal relationship, we use variation in leniency across patent examiners as a source of exogenous variation in granted patents. Patent examiner leniency has been recently used as an instrumental variable to estimate the effect of patents on subsequent cumulative innovation (Sampat and Williams, 2015) and on venture capitalbacked startup success (Gaulé, 2015; Farre-Mensa et al., 2017). The validity of this instrument is supported by interviews with employees of the United States Patent and Trademark Office (USPTO) regarding the allocation of patent applications to examiners (Cockburn et al., 2003; Lemley and Sampat, 2012), as well as by our own exogeneity tests.

Our empirical analysis is based on the career trajectories of 69,136 inventors who filed their first patent application with the USPTO between 2001 and 2012. By identifying individual inventors' career moves from patent application data, our results point to a negative effect of patenting on mobility. In particular, one additional patent granted (due to a "lucky" examiner assignment) decreases an inventor's probability of changing employers by 25 percent. This negative effect increases to 42 percent for "discrete" technologies (such as pharmaceuticals and chemicals), where individual inventions are more clearly linked to marketable products and patent rights protect them more effectively (Cohen et al., 2000). On the other hand, the estimated effect is much weaker in "complex" technologies (such as electronics), where a given product is typically associated with many potentially patentable elements, meaning that an individual patent confers less protection on the final product. Overall, these results suggest that, by providing firms with monopoly power over a given technology, patents make the human capital of the creators of the underlying innovation more specific to the current employer. Additional tests show that the negative effect of patenting on mobility is stronger for inventors with fewer co-authors and for inventors working outside the technological core of their firm, suggesting that patents play a stronger role in the absence of other sources of firm-specific human capital. Finally, and consistent with our specific human capital hypothesis, we document that patents most steeply decrease the mobility of inventors to firms that work in the same core technological areas as their current employers.

The results of our study provide new insights into several domains. First, we contribute to research on knowledge diffusion and inventor mobility by showing that the institutional effect of the patent offices on mobility is not neutral. Scholars have traditionally relied on patent 
data to examine the impact on mobility of institutional factors such as trade-secret laws or noncompete contracts (Fallick et al., 2006; Marx et al., 2009; Png and Samila, 2015) and inventors characteristics such as productivity (Hoisl, 2006; Palomeras and Melero, 2010). However, little is known about whether and how the mobility of those employees is itself affected by patents. Our study aligns with recent work by Agarwal et al. (2009) and Ganco et al. (2015), who show that the degree of litigiousness of patent-holding firms is related to the amount of knowledge that moving inventors can effectively transfer and, consequently, to inventor turnover rates. In this respect, our paper provides evidence on the causal role that patent grants play in the overall process. Second, our paper adds a dimension to the ongoing debate over the role of patents in innovation policy. The design of a patent system is expected to address the tradeoff between the incentive to innovate and the diffusion of knowledge. Our results suggest that, by reducing the inter-firm mobility of inventors, patents may preclude the transmission not only of formally protected knowledge but also of tacit technical and organizational knowledge. The findings also imply that patents may shift incentives to invest in inventive skills from the employee-inventors to the patent-holding employers. Finally, our results have an important methodological implication. Many research questions in the area of innovation have traditionally been addressed using data on granted patents, from mobility studies to knowledge spillover estimations and co-inventor network analyses. Our evidence indicates that future research should take into account the effect of patent grants on the behavior of inventors and subsequent knowledge flows in order to avoid potentially biased results.

\section{Background}

The thesis of this article is that patent grants make the human capital of inventors more specific to their employers. It builds upon the idea that patent rights provide their owners with an increased ability to protect their intellectual assets and, consequently, to obtain a monopoly over the underlying technology. ${ }^{1}$ In addition, the labor contracts of R\&D workers typically include provisions by which employers retain property rights over their employees' inventions. This implies that patents effectively constrain the inventor from freely using that protected knowledge. The consequences for mobility, however, are not straightforward.

The first element to take into account is the balance of incentives of current employers and rivals to bid for the inventor. Consider first the author of an innovation that, because of a lack of patent rights, is only weakly protected. On the one hand, the ability of competitors to replicate the invention would be clearly enhanced by employing the original inventor. Thus, they have incentives to poach her. On the other hand, the current employer may also have strong incentives to retain the inventor in order to secure monopoly profits by preventing her from moving to a competitor. The joint-profit effect (Budd et al., 1993) suggests that, in the absence of strong property rights, incumbents will have stronger incentives than their rivals to bid for their inventors, unless their products are differentiated enough in the market (Fosfuri et al.,

\footnotetext{
${ }^{1}$ Survey evidence gathered by Cohen et al. (2000) suggests that firms may prefer alternative mechanisms of protection, such as secrecy or lead time, over patents in a wide range of settings. Our study considers the universe of inventions for which an application for patent protection has been filed. Therefore, it seems reasonable to assume that applicants in this population expect to obtain an increase in protection from a granted patent.
} 
2001). ${ }^{2}$ Suppose that the incumbent now increases the protection of an innovation by obtaining a patent. To the extent that property rights prevent the unauthorized commercial exploitation of technological replicas by rivals, patents will eliminate the above-mentioned strategic incentives to either poach inventors (rivals) or retain them (incumbents) because rivals cannot use the inventors' knowledge for replication and incumbents do not need to retain the inventor to secure monopoly profits. Thus, the appropriation effect of patent grants on inventor mobility may be positive or negative, depending on the degree of differentiation among the products of the incumbent and its rivals. In a non-differentiated market, the incumbent's incentives to retain the inventor disappear with (strong) patents, so mobility increases with respect to a situation without property rights. In a differentiated market, rivals' incentives to poach the inventor tend to disappear with patents, and thus, mobility decreases with respect to a situation without patents.

A second important element to consider is the relevance of the inventors' knowledge for the successful implementation of an innovation by a patent holder. While patents may allow their holders to obtain monopoly profits when bringing the innovation to the market, the involvement of the inventor in implementation activities can enhance the exploitation of this monopoly power. This makes the human capital of inventors effectively complementary to patent protection. The development of an innovation into an actual product (or process) ready to be launched in the market (or internally implemented) is not a trivial task, and it usually benefits considerably from the involvement of the creator(s) of the innovation. In a study of licensing contracts for patented inventions in the biomedical industry, Hegde (2014) reports the use of clauses specifying the complementary knowledge that should be transferred to the licensee along with the patent in order to successfully develop the innovation. Some of these clauses explicitly require the personal involvement of the inventor in the process, as well as monetary compensation for their effort. These cases illustrate the importance of non-codified knowledge for the implementation of patented technologies, particularly the involvement of their creators. Maurseth and Svensson (2015) provide further evidence suggesting the importance of the inventor's involvement in successfully bringing an innovation to market using a sample of commercially exploited patents generated by small firms. This evidence indicates that inventors are inputs in the implementation of their innovation and that they are especially valuable when the latter is patent protected. According to this complementarity effect, therefore, patents increase the internal value of the inventor to the patent holder, generating some firm-specific human capital and decreasing the probability that inventors switch employers.

In sum, we expect patents to reduce inventor mobility to the extent that they confer monopoly power that can only be fully exploited by keeping the inventor in-house (complementarity effect) and that alternative employers develop sufficiently differentiated products (appropriation effect). In empirical terms, previous related research suggests that the relationship between property rights protection and mobility may go in this direction. Kim and Marschke (2005) provide evidence that innovative firms tend to file for patent protection more in contexts

\footnotetext{
${ }^{2}$ In a non-differentiated market, an incumbent's incentives to maintain a monopoly situation (as opposed to a duopoly one) will be greater than or equal to those of rivals seeking duopoly profits. As noted by Fosfuri et al. (2001), however, this is not necessarily the case if there is some product differentiation or if the intensity of competition is low.
} 
with highly dynamic R\&D labor markets. However, they do not specifically study the direction of the effect of patents on mobility. In a related study, Ganco et al. (2015) find that the outbound mobility of the inventors of patented innovations is significantly lower in innovative firms with strong reputations for patent litigation. Outside the realm of patent enforcement, Png and Samila (2015) show that the mobility of qualified workers is lower in U.S. states with stronger enforcement of trade-secret laws.

If patents have a detrimental effect on inventor mobility because their human capital becomes relatively more valuable to their current employer, we should expect that the impact on mobility is heterogeneous across contingencies. First, our argument that the negative effect of patents on mobility is caused by the monopoly power they confer implies that the size of the impact should differ with the effectiveness of patent protection across technology fields. Both the appropriation effect (resulting from changes in the balance of incentives to poach and retain the inventor) and the complementarity effect (arising from the role of the inventor in the implementation of the innovation) will be more intense when patents offer stronger protection. Therefore, the negative effect of patents on mobility will be more pronounced in settings of higher patent effectiveness.

Second, we expect other sources of inventors' firm-specific human capital to act as substitutes for patent protection. Workers' firm-specific skills are tied to a particular firm and have limited applicability to outside firms. This results in a lower relative outside value of employees' human capital in the labor market and leads to a lower probability of turnover (Becker, 1962). In particular, patents operate as a source of specificity of an inventor's human capital by creating a legally induced gap between the inside and the outside value of her skills that reduces her probability of moving. We expect this effect to be weaker when other sources of complementarity (either legally or technically induced) with the current employer make an inventor's skills firm specific. The reason is that if an inventor's skills are already firm specific, she will be unable to fully apply her skills at a new employer, even if the underlying knowledge is not patented. In contrast, when the inventor's skills are general and can be readily applied to alternative employers, patent protection should have a larger negative effect on mobility.

Third, obtaining a patent may affect different types of inter-firm moves differently. Inventors may be induced to leave their companies for a variety of reasons, and replicating their innovations elsewhere may be only one of them. The above discussion of how patents affect the balance of bids to appropriate the knowledge associated with the innovation only concerns firms that are close enough in the technological space to be able to implement this technology. Firms that are technologically distant can also be considered alternative employers of the focal firm's inventors, but they are less likely to be interested in the specific innovation than are technologically close competitors. Hence, the appropriation effect of patents on mobility will be weaker for moves to technologically distant employers. On the other hand, the complementarity effect will reduce the probability of moving to any alternative employer, since it only concerns the internal value of the employment relationship between the inventor and the patent-holder. Thus, we expect that even if patents reduce inventor mobility to both technologically distant and technologically close firms, the effect will be more pronounced for moves to the latter group of employers as long as they market sufficiently differentiated products. 


\section{Description of the data}

Our paper combines data from several sources. Our starting point is the USPTO Patent Examination Research (PatEx) dataset, which sources its information from the public Patent Application Information Retrieval (PAIR) database. PAIR contains detailed information on patent applications filed with the USPTO. For each application, it includes characteristics such as the filing date, application type, patent class and subclass codes and current application status, as well as data about the examination, such as the identity of the assigned examiner and the "art unit" to which he belongs. From this dataset, we identify every original utility patent application filed between 2001 and 2012, which totaled 3.6 million applications. We are constrained to this time period due to data availability. The PAIR dataset contains data only on applications that have been published (i.e., that are open to public scrutiny), and it was not until late 2000 that applications were made public before a patent was granted following the implementation of the American Inventors Protection Act (AIPA). This means that since November 2000, publication happens regardless of whether the patent is granted, whereas previously, only applications that were eventually issued patents were published. As Graham et al. (2015) report, PAIR has very good coverage (95\%) of regular utility filings from 2001 to 2012 (after that, truncation due to the publication lag affects coverage). ${ }^{3}$

We next turn to the information available from the USPTO Patent Assignment Dataset, since the PAIR database does not identify the assignee (i.e., the firm) responsible for filing the patent. Before September 2012, the USPTO considered the inventor to be the owner of a patent application. However, inventors typically have contractual obligations to transfer ownership to their employer. In order to do so, it was necessary to submit a chain of title from the original owner (i.e., the inventor) to the assignee (i.e., the firm) to the patent office so that the legal assignment could be made. ${ }^{4}$ The dataset tags those assignments, allowing us to identify the assignee and the presumed employer of an inventor. From our original set of patent applications, we identify 2.8 million applications that were re-assigned from the inventors to the employers.

Thereafter, we use data from the PatentsView initiative (www.patentsview.org) to identify the inventors listed in our sample of applications and compile their career histories. This dataset contains the results of the disambiguation algorithm specific for inventor data provided in $\mathrm{Li}$ et al. (2014) and Balsmeier et al. (2015), which allows the robust identification of individual inventors across patent applications (since 2001) and granted patents (since 1976). ${ }^{5}$ Through these data, we can identify 2.1 million disambiguated individual inventors.

This initial set of inventors is substantially reduced due to the restrictions we impose. First, we focus our analysis on inventors who filed their first patent application between 2001 and

\footnotetext{
${ }^{3}$ The remaining $5 \%$ of applications corresponds to two categories: those that were abandoned before the 18month publication lag and those that opted out of pre-grant publication (thus relinquishing the possibility of international protection) and for which patents were not eventually granted (Graham et al., 2015). According to these authors, who had access to internal USPTO application records, the applications covered by PatEx are very similar to the population of USPTO applications.

${ }^{4}$ See 37 CFR 3.71 (pre-AIA), 35 U.S.C. 261 and Marco et al. (2015) for details.

${ }^{5}$ We are grateful to the PatentsView team for sharing this data with us. PatentsView is supported by the Office of the Chief Economist at the USPTO, with additional support from the U.S. Department of Agriculture (USDA). The PatentsView platform was established in 2012 and is a collaboration among the USPTO, USDA, Center for the Science of Science and Innovation Policy at the American Institutes for Research, University of California, Berkeley, Twin Arch Technologies, and Periscopic.
} 
2012. This sample represents a selection of inventors who are in their early careers, that is, in the ten first years (at most) of inventive activity. We select these inventors for two main reasons. Primarily, the initial steps of an inventor's career are more likely to be affected by the outcome of one or a few patent applications. Thus, if an effect of patents on mobility exists, it will be more clearly detected among inventors beginning their careers. Moreover, regression to the mean in random processes eliminates variation in average patent examiner leniency among inventors with a large number of applications. Thus, our identification strategy would be less effective for the subpopulation of very experienced inventors. Accordingly, we select only inventors with no prior patenting experience before our sample period (i.e., before 2001).

Second, given our aim to detect the impact of the decision of the patent office, we focus on inventors who receive at least one decision on an application during our sample period. In particular, we require that they receive a first decision on their application prior to 2012 in order to ensure that we have at least a nine-month window in which to observe mobility for the last cohort in the data. ${ }^{6}$

Third, given our interest in employee inventors, we further restrict our sample to inventors who started their careers (as measured by their patent filings) at a company. In order to capture them, we select applications assigned to originating firms included in the Standard and Poor's (S\&P) Capital IQ database, which provides the names and transactions (such as mergers and acquisitions) for the most extensive set of public and privately held U.S. firms (to the best of our knowledge). In order to match the firm names from Capital IQ with the assignee names, we first apply the name standardization procedure used in the NBER patent data project. ${ }^{7} \mathrm{We}$ then run the Jaro-Winkler algorithm (developed to assist in the disambiguation of names in the U.S. Census) to correct for typos and misspellings, grouping together records with an overlap of $90 \%$ or higher. Finally, we keep the final list of standardized assignee names that coincide exactly with firm names in Capital IQ.

Following the previous literature, we infer inventor mobility based on a change in the assignee between two consecutive applications (see, e.g., Almeida and Kogut, 1999; Trajtenberg et al., 2006; Marx et al., 2009; Singh and Agrawal, 2011; Ganco et al., 2015). This approach has a number of acknowledged limitations (Palomeras and Melero, 2010; Ge et al., 2016). First, an inventor's career can only be tracked if she is included repeatedly in patent applications. Otherwise, she is censored out of the sample. One potential concern is that inventors whose applications have not been granted may be less likely to apply again in the future. ${ }^{8}$ To the extent that this attrition effect concerns similarly moving inventors and stayers, it would not affect our estimation of the relationship between patent grants and mobility. A more serious concern is that differences among firm patenting policies lead inventors that switch employers to differ from stayers in their probability of being included in a future application. After all, applying for patents is to a large extent a firm-level decision, and there may be substantial heterogeneity among firms in the intensity of patent use. All the inventors in our population have, by definition, been included in a patent application by their initial employers. Thus, it

\footnotetext{
${ }^{6}$ Note that our observation period effectively runs until September 2012 when the previously mentioned legal process to reassign ownership from inventors to their firms was changed.

${ }^{7}$ See https://sites.google.com/site/patentdataproject.

${ }^{8}$ For example, while $50.6 \%$ of individuals whose first patent application was not granted never filed an application again, the corresponding percentage decreases to $44.4 \%$ for individuals whose first application was granted.
} 
is natural to expect that all of them are initially employed by a firm with relatively high levels of patent intensity and that moving inventors will switch, on average, to less patent-intensive employers. This would imply that that our overall mobility rates would be underestimated and, more importantly, that our estimated effect of patent grants on mobility would be subject to attenuation bias. We address this issue in Section 5.3.

Second, identifying inventors through the names that appear in patent documents may lead to misclassification errors. We mitigate them by using the disambiguation algorithm provided by Balsmeier et al. (2015). As remarked by Ge et al. (2016), other potentially important sources of misclassification in tracking mobility with patent data are the inability to detect the exact point in time at which a move takes place (not problematic for our study), and the recording as moves of contract R\&D, collaborations, mergers or acquisitions. We address this last problem by imposing some restrictions in order to consider a change in assignee as an actual move: (i) we do not consider changes in the assignee that imply returns to an original employer in less than one year from the supposed move under the assumption that they probably reflect contract research or collaborations; and (ii) we do not consider apparent changes in employers due to mergers and acquisitions, which are detected through information provided by Capital IQ. The existence of some remaining misclassification error is unavoidable due to the nature of the large-scale representative sample used in our study.

Thus, our final sample consists of inventors who started their research lives at one of our identified Capital IQ firms during the period 2001-2011 and who receive a first decision on a patent application prior to 2012. We track inventors from their first application until they move or until their last application (during the sample period) with the originating firm. The resulting dataset comprises 69,136 first-time inventors employed by 2,883 originating firms that filed 404,016 patent applications during the sample period. In total, we detect 13,984 firstemployer changes for those inventors, averaging 0.20 moves per inventor.

\section{Econometric modeling strategy}

\subsection{Baseline specification}

To identify how the approval of an inventor's patent application affects subsequent mobility, we estimate the likelihood that an individual changes her employer between application year $t$ and application year $t+1$, conditional on not having moved at $t$. We use a linear probability model to estimate the hazard that an inventor moves:

$$
\text { Probability }_{i t}\left(Y_{i, t+1}=1\right)=\alpha+\beta \text { Patents } \text { granted }_{i t}+\gamma Z_{i t}+\delta S_{i}+\varepsilon_{i t},
$$

where $i$ indexes inventors, and $t$ is an ordinal index of application year (i.e., $t=1$ refers to the first year in which the inventor files an application, $t=2$ corresponds to the second year when she files an application, etc.). The dependent variable, $Y_{i, t+1}$, is an indicator that equals one if an inventor moves between $t$ and $t+1$. Note that we consolidate the information on applications on an annual basis, so our measure of mobility records whether the inventor changed employers 
at least once during that observation window. Our main variable of interest, Patents granted $_{i t}$, is the total number of patents issued to inventor $i$ up to (and including) spell $t$. The vector $Z_{i t}$ contains a range of time-variant covariates. First, and most importantly, $Z_{i t}$ contains the total number of applications filed by inventor $i$ up to spell $t$. We also condition on the time elapsed since the inventor's first decision year, allowing mobility decisions to be shaped by seniority. To account for sectoral differences in mobility rates, we include indicators for six non-exclusive NBER categories in which applications are classified. Finally, $S_{i}$ represents the year in which the inventor receives her first decision from the patent office. This cohort indicator controls for the fact that inventors entering later in the panel have less time to move than do those entering earlier. We cluster standard errors at the inventor level.

\subsection{Identification strategy}

As discussed in the introduction, an important concern is that $\beta$ will likely be biased upwards, since it captures the combined impact of patents granted and omitted inventor characteristics. For example, inventors of higher quality are more likely to be the authors of inventions that meet USPTO criteria for approval. ${ }^{9}$ Since those inventors are also more likely to be hired away (Palomeras and Melero, 2010), this may confound any true causal effect. To overcome this identification challenge, we use examiner leniency as an instrument for whether an inventor's applications are approved by the patent office and estimate Eq. (1) using a two-stage least squares (2SLS) approach (see Gaulé, 2015; Sampat and Williams, 2015; Farre-Mensa et al., 2017). This instrument was first proposed by Sampat and Williams (2015) based on the work of Lemley and Sampat (2012) and Cockburn et al. (2003) on the processes and outcomes of patent examination at the USPTO. We next describe this process to illustrate the rationale for the instrument.

\subsubsection{Rationale for the instrument: The examination process}

Patent examiners at the patent office are key figures in the examination process of a patent application. Their decisions determine eventual approval or rejection. Recent studies suggest that the odds of receiving a patent depend on the characteristics of the particular examiner assigned to the application (Lemley and Sampat, 2012; Frakes and Wasserman, 2016). In their sample, Lemley and Sampat (2012) find an 11-percentage-point difference in the grant rate between the least and the most experienced examiners who check applications related to a given technology. Frakes and Wasserman (2016) report differences in the odds of patent approval by examiner cohort (i.e., the year in which they were hired), which they attribute to differences in the training received that mirrored patent office policies at that time. There is also evidence that certain characteristics of granted patents differ by examiner. ${ }^{10}$ Cockburn et al. (2003) and Lichtman (2004) acknowledge that patent examination is not a mechanical process and,

\footnotetext{
${ }^{9}$ The USPTO assesses whether applications should be granted patents based on the following five criteria: patent eligibility (35 U.S.C. 101), novelty (35 U.S.C. 102), non-obviousness (35 U.S.C. 103), usefulness (35 U.S.C. 101), and an application that satisfies the disclosure requirements (35 U.S.C. 112).

${ }^{10}$ In a small and very selective sample (180 granted patents brought to the Court of Appeals at the end of the nineties), Cockburn et al. (2003) note that characteristics such as prior citations introduced by the examiner, citations received afterwards and the odds of being declared invalid by the courts vary with the characteristics of the examiners.
} 
therefore, examiners necessarily enjoy some discretion in how they conduct the examination and determine its outcome. Nevertheless, the allocation of applications to examiners at the USPTO follows certain structured steps that guarantee virtually random assignment within a given technological area (Cockburn et al., 2003; Lemley and Sampat, 2012).

At the USPTO, patent applications are received by a central office, where they are assigned an application number, a patent class and subclass codes and allocated accordingly to one of the art units in charge of the examination process. Art units are groups of examiners that specialize in a given set of technologies (there are more art units than patent classes but fewer than subclasses). Once a patent is allocated to an art unit, a supervisory patent examiner (SPE) receives the application and assigns it to a specific examiner. Each art unit is an independent administrative division and has discretion in how work is organized, including how applications are allocated to examiners. Interviews with patent examiners conducted by Lemley and Sampat (2012) reveal that supervisory examiners make most final decisions on the assignment of applications to examiners on a quasi-random basis (e.g., according to docket management needs or following arbitrary rules, such as the last digit of the application number). There is no evidence from these interviews that SPEs engage in any substantive evaluation of applications in order to detect their patent-worthiness. Therefore, it is unlikely that they assign applications to certain examiners according to such characteristics. Both Lemley and Sampat (2012) and Sampat and Williams (2015) show that patent applications assigned to lenient and strict patent examiners have similar observable characteristics at the time of application (number of pages, family size and number of claims). In Appendix A.1, we replicate this exercise for other relevant pre-determined factors, such as the size of the applicant firm or references to the patent and non-patent literature submitted in the application. Our results do not show a significant relationship between these factors and examiner leniency. Hence, the evidence at hand suggests that the assignment of applications to examiners can be reasonably assumed to be essentially random within a given art unit. Consequently, we follow Sampat and Williams (2015), Gaulé (2015), and Farre-Mensa et al. (2017) in using examiner leniency as an instrument for application approval.

\subsubsection{The instrument: Average Examiner Leniency}

Our objective is to obtain an instrumental variable for the number of applications granted to an inventor up to a given point in time. We start by operationalizing examiner leniency at the application level. In the spirit of Gaulé (2015), we compute time-varying measures of leniency as follows:

$$
E_{j k a t}=\frac{\text { Grants }_{\text {kat }}-1\left(\text { Grant }_{j}=1\right)}{\text { Reviews }_{k a t}-1}
$$

and

$$
U_{j a t}=\frac{\text { Grants }_{a t}-1\left(\text { Grant }_{j}=1\right)}{\text { Review }_{a t}-1},
$$

where $E_{j k a t}$ is the approval rate of examiner $k$ in art unit $a$ assigned to review patent application $j$ submitted at time $t$. Reviews $s_{k a t}$ and Grants $s_{k a t}$ are the numbers of applications examiner $k$ has 
reviewed and granted, respectively, in art unit $a$ in the same application year as $j .{ }^{11}$ Similarly, $U_{\text {jat }}$ is the approval rate of art unit $a$ and is constructed as the share of reviewed applications filed in the same year as application $j$ that were granted by art unit $a$, excluding the focal patent. ${ }^{12}$ The difference between $E_{j k a t}$ and $U_{j a t}$ is hence the relative leniency faced by an inventor who files patent application $j$ in year $t$ assigned to examiner $k$ within art unit $a$. For a single patent application, the corresponding examiner relative leniency, $E_{j k a t}-U_{j a t}$, is a suitable instrument for whether that application is granted. However, we are interested in obtaining an instrument for the inventor's total number of applications granted up to a given time. We account for this by averaging $E_{j k a t}-U_{j a t}$ across all patents applied for by inventor $i$ up to year $t$ :

$$
L_{i t}=\frac{1}{n_{i t}} \sum_{j=1}^{n_{i t}}\left(E_{j k a t}-U_{j a t}\right) .
$$

Unlike previous literature using examiner leniency as an exogenous source of variation in granted patents, our study averages leniency at the inventor level. This allow us to obtain an instrument for an inventor's stock of granted patents ${ }^{13}$, but prevent us from using within-art-unit technology fixed effects in our main specifications. In Appendix A.2, we provide some evidence suggesting that this is not a concern.

\section{Patent grants and inventor mobility}

\subsection{Descriptive statistics}

Table 1 provides descriptive statistics for the main variables used in this study. The unit of observation in our analysis is the inventor-application year. Accordingly, the figures indicate that, on average, $11 \%$ of inventors change employers between two application years. Inventors are, on average, responsible for 2.2 granted patents.

\footnotetext{
${ }^{11}$ Given that there may be concerns about measurement error in leniency when the set of applications is small, we define some threshold values (10,20, and 50) and experiment with considering only cases for which the number of reviewed applications per examiner, year and art unit exceeds these thresholds. If anything, results are stronger with these restrictions.

${ }^{12}$ Note that our instrument differs from that proposed by Gaulé (2015) in two respects. First, while the author considers the overall approval rate of an examiner, we follow Sampat and Williams (2015) and Farre-Mensa et al. (2017) in adjusting for each art unit. Our reason for doing so is that in our sample period, on average, $39 \%$ of examiners reviewed patent applications for multiple art units in the same year. Second, our equations differ in the denominator, since we use the number of patent applications reviewed rather than the number of applications filed. Nothing hinges on the use of the leniency measure in Gaule (2015), however.

${ }^{13}$ All the main results of this paper are robust to considering only inventor mobility in the spell after the first application decision. The specific analysis showing this is available upon request from the authors.
} 
Table 1

Descriptive statistics

\begin{tabular}{lcccccc}
\hline Variable & Mean & SD & Min & Median & Max & Observations \\
\hline Move & 0.11 & & 0 & 0 & 1 & 131,485 \\
\# of patents issued & 2.2 & 3.7 & 0 & 1 & 136 & 131,485 \\
\# of applications filed & 7.7 & 11.1 & 1 & 4 & 305 & 131,485 \\
Examiner leniency & 0.004 & 0.09 & -0.86 & 0.01 & 0.74 & 131,485 \\
Years since 1st decision & 3.0 & 2.0 & 1 & 2 & 11 & 131,485 \\
\# of co-inventors & 11.0 & 12.4 & 0 & 7 & 226 & 131,485 \\
\# of uspc classes & 2.9 & 2.4 & 1 & 2 & 49 & 131,485 \\
\% of applications in firm's core & 0.30 & 0.39 & 0 & 0 & 1 & 131,485 \\
\# of applications per firm & 1,263 & 1,776 & 1 & 449 & 7,803 & 131,485 \\
Enforceability index & -0.72 & 1.7 & -4.2 & -0.07 & 1.6 & 47,611 \\
\hline
\end{tabular}

\subsection{Baseline specification}

Table 2 provides the main results. In column 1 of Table 2, we begin with the OLS estimates of the baseline specification relating mobility to the number of patents granted and additional controls. We find a weak, positive and significant correlation between patent grants and mobility. This relationship cannot be interpreted as causal, however. As argued above, there are reasons why we should expect unobservable factors to affect both the extent to which inventor's patent applications are approved by the USPTO and subsequent mobility.

Moving to the instrumental variable approach, column 2 presents the first stage in which we regress the number of patents issued on examiner leniency (and all other controls). As expected, the instrument is positive and highly significant: a one standard deviation increase in the leniency of the examiner assigned to review an inventor's patent application is associated with a seven-percentage-point increase in the number of patents issued for the average inventor. The first-stage $F$-statistic of the excluded instrument is large (796) and well above the rule of thumb for weak instruments (see, e.g., Stock and Yogo, 2005), indicating that the instrument explains a substantial part of the variation in granted patents. Column 3 reports the result from the second-stage regressions estimating Eq. (1), with the main variable of interest replaced with the fitted value of \# of patents issued from the first-stage regression. The coefficient is strongly negative and significant at the $1 \%$ level. The point estimate implies that an exogenous increase in one successful patent application reduces the probability of moving by $2.8 \%$, which represent a $25 \%$ decrease over the conditional sample probability of $11 \%$. This is a result of economic significance. The substantial difference between the OLS and IV estimates highlights the importance of controlling for the endogeneity of patent grants and indicates a strong positive correlation between \# of patents issued and the disturbance in the mobility equation, inducing a large upward bias if we treat USPTO decisions as exogenous.

For the ease of estimation and interpretation, we use linear probability models as our main specifications throughout the paper. In column 4 of Table 2, however, we report the results from a probit model where we implement the instrumental variable estimator by using the control function method (see Blundell and Powell, 2004). This leads to qualitatively and quantitatively similar results for the coefficients on \# of patents issued and, hence, supports the reasonableness of our linear 2SLS model approximations of the average partial effects as suggested, for example, by Wooldridge (2014).

Overall, these instrumental variable specifications provide strong evidence that patents cause, on average, a decrease in the subsequent mobility of early-career inventors. This result suggests 
that patents make the human capital of inventors more specific to their employers. In the next subsection, we provide a series of robustness checks to address alternative explanations, while in Section 6, we provide additional evidence on the heterogeneity of the estimated effect to strengthen our interpretation.

Table 2

Patent grants and inventor mobility

\begin{tabular}{|c|c|c|c|c|}
\hline \multirow[b]{2}{*}{ Estimation method } & Base & \multicolumn{3}{|c|}{ Controlling for endogeneity } \\
\hline & OLS & $\begin{array}{c}\text { OLS } \\
\left(1^{\text {st }} \text { st. }\right) \\
\# \text { of pats }\end{array}$ & $\begin{array}{c}2 \mathrm{SLS} \\
\left(2^{\text {nd }} \mathrm{st} .\right)\end{array}$ & $\begin{array}{l}\text { Probit } \\
\left(2^{\text {nd }} \text { st. }\right)\end{array}$ \\
\hline Dependent variable & $\begin{array}{c}\text { Move } \\
(1)\end{array}$ & $\begin{array}{l}\text { issued } \\
(2)\end{array}$ & $\begin{array}{l}\text { Move } \\
(3)\end{array}$ & $\begin{array}{l}\text { Move } \\
(4)\end{array}$ \\
\hline \# of patents issued & $\begin{array}{c}0.001^{* * *} \\
(0.000)\end{array}$ & & & \\
\hline Examiner leniency & & $\begin{array}{c}1.705^{* * *} \\
(0.060)\end{array}$ & & \\
\hline \# of patents issued (instr.) & & & $\begin{array}{c}-0.028^{* * *} \\
(0.006)\end{array}$ & $\begin{array}{c}-0.022^{* * *} \\
(0.005)\end{array}$ \\
\hline Years since $1^{\text {st }}$ decision $(\mathrm{L})$ & $\begin{array}{c}0.038^{* * *} \\
(0.002)\end{array}$ & $\begin{array}{c}1.310^{* * *} \\
(0.014)\end{array}$ & $\begin{array}{c}0.077^{* * *} \\
(0.008)\end{array}$ & $\begin{array}{c}0.069^{* * *} \\
(0.006)\end{array}$ \\
\hline First decision year FE & Yes*** & Yes*** & Yes*** & Yes*** \\
\hline \# of applications filed $\mathrm{FE}$ & Yes*** & Yes*** & Yes*** & Yes*** \\
\hline Technological class FE & Yes*** & Yes*** & Yes $^{* * *}$ & Yes*** \\
\hline First-stage $F$-statistic & & 796 & & \\
\hline $\begin{array}{l}N=131,485 . \text { Number of } \\
\text { Estimation period is } 2001- \\
\text { inventor (in parentheses). C } \\
\text { from a probit model with e } \\
\text { *** } p<0.01 \text {. }\end{array}$ & $\begin{array}{l}\text { nventors: } \\
\text { 11. Robu } \\
\text { umn (4) }\end{array}$ & $\begin{array}{l}69,136 . \mathrm{N} \\
\text { t standard } \\
\text { splays the } \\
\text { egressors. }\end{array}$ & mber of & $\begin{array}{l}\text { ms: } 2,883 \\
\text { ustered by } \\
\text { inal effects } \\
{ }^{*} p<0.05\end{array}$ \\
\hline
\end{tabular}

\subsection{Robustness checks}

In this section, we briefly summarize a variety of tests that allow us to confirm the robustness of our main finding. Results are reported in Appendix A.3.

First, in column 1 of Table A3, we estimate a specification that incorporates fixed effects at a more fine-grained technology level. In our main specification, we use the six broad (one-digit) NBER technology fields, whereas in this specification we include fixed effects that capture the 37 (two-digit) NBER sub-categories. The estimated coefficient on patent grants is identical to the baseline coefficient.

Second, we check to what extent our estimated coefficient of interest may be subject to attenuation bias. As suggested in Section 3, this would be the case if moving inventors were less likely to apply for new patents than stayers. We replicate the main analysis, presented in Table 2, for the sub-sample of inventors who obtained at least one decision on their patent applications relatively early in our sample (i.e., prior to 2007). For this group of inventors, the observation window is longer and, therefore, censoring is less likely (we have at least a 5-year time window to observe another application). While $46.2 \%$ of first-time inventors are excluded from our main sample because they are only observed once, this percentage is reduced to $26.8 \%$ for this sub-sample. The results for this sub-sample are reported in column 2 of Table A3 and are qualitatively and quantitatively similar to those of our baseline estimatation.

Third, we address the concern that our results could be driven by the sub-sample of inventors whose employers went out of business. If patents affect firm survival (as suggested by Farre- 
Mensa et al., 2017), we could be detecting purely mechanical moves following inventors' patent rejections (i.e., moves motivated by their employer's bankruptcy). In column 3 of Table A3, we report the results of a restricted analysis wherein we consider only moves away from source firms that have at least one patent filed in the years after the registered employer change. Restricting the analysis to this sub-set of moves produces nearly identical results to those of our baseline estimation.

Fourth, we examine whether the estimated effect of patent grants on inventor mobility is monotonic. To check this, we include the instrumented squared term of \# of patents issued in our model. As column 4 of Table A3 shows, the quadratic term is close to zero and not statistically significant, whereas the linear term remains negative and significant, with a point estimate that is substantially higher than the baseline estimate.

Fifth, one might worry that the effect we observe of patents on mobility is driven by the threat of litigation posed by a few patent holders. As Ganco et al. (2015) note, patent holders vary in their "toughness" in IP litigation, which is correlated with the probability that an inventor exits the firm. To account for this difference, we include the lagged three-year moving sum (i.e., from $t-1$ to $t-3$ ) of the number of patent infringement lawsuits filed by the focal employer (Litigiousness) in the main specification. We obtain this information from the Patent Litigation Docket Reports (publicly available through the USPTO website), which contains all patent litigation cases reported by U.S. district courts to the USPTO between 1963 and 2015. In column 5 of Table A3, we can observe that the coefficient on \# of patents issued remains identical to the baseline coefficient, while the coefficient on Litigiousness is negative and significant (as expected from prior research). We also interact the effect of patents on mobility with the proxy for IP toughness. In column 6 of Table A3, we report a negative but non-significant interaction and an estimated coefficient on patent grants of a very similar magnitude to that of the baseline estimate. Hence, patent rights decrease inventor mobility even for employers with low litigation profiles.

Finally, in our last robustness test, we extend the concept of patent protection beyond the granted/non-granted dichotomy and focus on the number of approved claims as a more finegrained measure of this concept: the scope of the patent. Because of our reliance on examiner leniency as an instrumental variable for patent approval, it is likely that the results presented in Table 2 represent local average treatment effects of an additional granted patent for the group of inventors producing innovations around the margin of approval and rejection. This analysis of the effect of approved claims allows us to evaluate the effect of a marginal increase in the scope of protection, which may happen at any point on the distribution of patentability. Each claim in a patent document describes in technical terms a different element of the protected technology. As Lanjouw and Schankerman (2001) state, patent claims delimit the boundaries of the legal protection conferred by the patent. A larger set of claims implies that the patent covers a broader share of the technological space. Non-granted patents obviously have no approved claim, and an increasing number of claims implies an increasing scope of protection for the patent holder. The applicant's incentive is to make claims that are as broad as possible in the application, as the examiner can limit these claims during the examination process (Lanjouw and Schankerman, 2001). The scope of patent protection is therefore affected by the examination process and is 
influenced by examiner leniency. More lenient examiners not only grant more patents but also allow a larger number of claims per patent (Cockburn et al., 2003; Lemley and Sampat, 2012). Consequently, examiner leniency can also be used as an instrumental variable to estimate the effect of a broader scope of patent protection on inventor mobility.

Table A4 presents the estimated effect of the average number of approved claims granted per application on an inventor's likelihood of moving. The number of claims can be readily obtained from patent documents and is available from USPTO datasets. The results are qualitatively similar to those of the analysis of patents granted. Column 2 indicates that examiner leniency is also a strong instrument for approved claims. Column 3 presents the second stage, with a negative and significant coefficient estimate on Avg. \# of claims issued, suggesting that a one-unit increase in the number of approved claims reduces the probability of moving by 0.3 percentage points - a $2.8 \%$ relative decrease in the probability of leaving. To examine the extent to which these results are driven by the fact that non-granted patents have zero approved claims, we repeat the analysis for the sub-sample of granted patents. As the coefficient from the last column of Table A4 shows, the estimated relationship between approved claims and mobility remains negative and significant. ${ }^{14}$ Overall, these results suggest that the main finding of this paper, i.e., the negative effect of patent protection on inventor mobility, is robust to considering the effect of patent scope, a more fine-grained measure of patent protection than patent grants. Consequently, they indicate that the estimated effect is not driven by a subset of inventors whose creations lie around the approval threshold but that it is a more general phenomenon.

\section{Heterogeneous impact of patent grants}

The previous section documents a negative effect of patent protection on inventor mobility, which is consistent with the idea that patent rights make the human capital of inventors specific to their employers. In this section, we explore several sources of heterogeneity in the relationship between patent grants and mobility in order to evaluate the existence of further evidence supporting that proposition. We first examine variations in the effect across technology areas. By drawing on the distinction between discrete and complex technologies outlined by the existing literature, we assess whether the negative effect of patenting on mobility is more pronounced for discrete technologies, where patents arguably provide stronger protection. Second, we explore the role of different sources of firm specificity affecting an inventor's stock of human capital. We examine whether in such cases patents play a less important role as a mechanism that turns inventor's knowledge into firm-specific capital and, thus, affect mobility less intensely. Finally, we examine whether patenting makes an inventor especially less likely to move to firms that are technologically similar to her current employer.

\subsection{Variation across technology fields}

Our argument is that the negative effect of patents on mobility presented in the previous section should be particularly strong in contexts where patents are more effective. The tradi-

\footnotetext{
${ }^{14}$ The results from this last piece of evidence, however, have to be interpreted with caution, since excluding inventors without granted patents from the analysis is likely to induce some sample selection bias.
} 
tional dichotomy between complex and discrete technologies is particularly useful in this respect. Mansfield (1986) and Levin et al. (1987) find that patenting is a key strategy for appropriating returns to R\&D in pharmaceuticals and chemicals, while it is less important in most other industries. Cohen et al. (2000) push this issue further and suggest that these differences are linked to the nature of the technology and to the physical characteristics of the products. Their rationale is that the number of patentable elements in a product importantly affects the way patents are used and, in turn, the degree to which they contribute to effective protection. In discrete industries, new products typically build on a few clearly identifiable features. Hence, only one or a few patents are required to achieve effective protection against imitation. This is the case in the pharmaceutical and chemical industries, where compounds are typically adequately protected by single patents. In contrast, new products in complex industries, such as electronics, require inputs from numerous complementary components, typically protected by patents held by an array of third parties. This makes the protection conferred by a single patent on a new component inherently less valuable, since it is necessary to have or acquire the rights on other proprietary elements to bring a new product to market. For these reasons, patents are reported to be less effective against imitation in complex product industries relative to alternatives such as secrecy, lead time or complementary capabilities (Cohen et al., 2000). ${ }^{15}$ Therefore, we should observe that the negative impact of patents on inventor mobility is stronger in discrete (compared to complex) technology fields.

In order to empirically identify the technology field for each patent application, we rely on the NBER categorization. As there is no widely accepted classification that links those categories to discrete or complex technology areas, we focus on the clear-cut cases identified in the prior literature. Following Levin et al. (1987) and Cohen et al. (2000), we classify chemicals (category 1) and drugs (sub-category 31 ) as discrete and computers and communications (category 2), medical instruments (sub-category 32), biotechnology (sub-category 33) and electric and electronics (category 4) as complex technology fields. ${ }^{16}$ We then aggregate this information at the inventor-application year level and construct two time-variant dummy variables, Discrete and Complex, that equal one if the inventor's largest share of applications up to spell $t$ belongs to discrete or complex technology classes, respectively, and zero otherwise. ${ }^{17}$ In our sample, the average mobility rate between two application years is $13 \%$ for inventors in discrete areas and $10 \%$ for those in complex areas.

\footnotetext{
${ }^{15}$ This claim is also line with the results of econometric studies that attempt to quantify the private value of patent protection across sectors (see, e.g., Lanjouw, 1998; Arora et al., 2008).

${ }^{16}$ Traditionally, biotechnology was classified as discrete due to its intrinsic technological characteristics. However, the possibility of patenting gene fragments since the late nineties contributed to the fragmentation of the patent rights needed for the commercialization of a product in this area (Cohen et al., 2000). Thus, following recent papers, such as Galasso and Schankerman (2015), we classify biotechnology as complex. The results are robust to the exclusion of biotech as a complex field.

${ }^{17}$ Because some technological areas are neither complex nor discrete, some 19,234 inventor-year observations are not assigned to either category.
} 
Table 3

Technological areas

\begin{tabular}{lcccc}
\hline $\begin{array}{l}\text { Estimation method: 2SLS } \\
\text { Sample }\end{array}$ & $\begin{array}{c}\text { All } \\
\text { Dependent variable: Move }\end{array}$ & $\begin{array}{c}\text { Discrete } \\
(1)\end{array}$ & $\begin{array}{c}\text { Complex } \\
(3)\end{array}$ & $\begin{array}{c}\text { Discrete and } \\
\text { complex } \\
(4)\end{array}$ \\
\hline \# of patents issued (instr.) & $-0.027^{* *}$ & $-0.054^{* * *}$ & $-0.022^{* *}$ & $-0.020^{* *}$ \\
& $(0.011)$ & $(0.014)$ & $(0.009)$ & $(0.009)$ \\
\# of patents issued & -0.026 & & & $-0.034^{*}$ \\
$\quad \times$ Discrete (instr.) & $(0.018)$ & & & $(0.019)$ \\
\# of patents issued & 0.008 & & & \\
$\quad \times$ Complex (instr.) & $(0.014)$ & & & $0.063^{*}$ \\
Discrete & $0.070^{* *}$ & & & \\
& $(0.032)$ & & & \\
Complex & 0.008 & & & 110,330 \\
& $(0.029)$ & & & 58,296 \\
$N$ & & & & \\
\# of inventors & 131,485 & 23,991 & 88,260 & \\
\# of firms & 69,136 & 13,632 & 46,498 & 1,823 \\
Wald $\chi^{2}$ & 2,883 & 1,277 & & \\
\hline
\end{tabular}

Estimation period is 2001-2011. Robust standard errors are clustered by inventor (in parentheses). All regressions control for the number of years since inventor's first decision (log), as well as fixed effects for the number of applications filed by the inventor and the year of inventor's first decision. Wald tests for differences in coefficients between \# of patents issued $x$ Discrete and \# of patents issued $x$ Complex. ${ }^{*} p<0.10,{ }^{* *} p<0.05,{ }^{* * *} p<0.01$.

We examine the impact of patents on mobility by technology field using the instrumental variable discussed above. Column 1 of Table 3 provides the estimates obtained using the full sample. Specifically, we augment Eq. (1) by including two instrumented interaction terms to capture how different appropriability regimes alter the effect of patents on inventor mobility. The coefficient on the first interaction term, \# of patents issued $x$ Discrete, is large and negative, while that of \# of patents issued $x$ Complex is small and positive, although neither is statistically significant. The corresponding Wald test indicates, however, that these two coefficients are statistically significantly different from one another. These findings indicate, as predicted, that the negative effect of patents on inventor mobility is stronger when inventors' patent filings are concentrated in discrete technologies instead of complex fields. Columns 2 and 3 present the results of estimating our baseline 2SLS model separately for the subsamples of inventors working mainly in complex technologies and those working mainly in discrete fields. The results show that the effect of patent grants is large, negative and significant among inventors whose main expertise lies in a discrete technology field, whereas it is smaller among inventors in complex areas. One additional patent granted is expected to reduce the probability of moving by $2.2 \%$ for inventors in a complex field (a $22 \%$ decrease over the conditional sample probability of $10 \%$ ) and by $5.4 \%$ for those in a discrete field (a $42 \%$ decrease over the conditional sample probability of $13 \%$ ). Finally, column 4 provides estimates using the combined sub-samples and interacting \# of patents issued with Discrete. Consistent with the previous findings, the coefficient on the interaction term is negative and significant at the $10 \%$ level.

\subsection{Other sources of firm-specific human capital}

A second analysis considers the extent to which different sources of an inventor's firm-specific human capital shape the effect of patents on mobility. In particular, our arguments suggest that the effect will be less negative when other types of human capital firm specificity are already in 
place, and it will be more intense otherwise. To explore this question, we look at cases in which the inventor's knowledge becomes more valuable when implemented in collaboration with that of other inventors in the company or in conjunction with some of the current employer's key assets. We also analyze whether the effect of patents is attenuated in the presence of another legally induced source of firm specificity: non-compete covenants.

In the context of innovation studies, the literature suggests two potential sources of firm specificity for inventors' human capital. First, Hayes et al. (2006) argue that firm specificity derives from complementarities with the firm's other workers. In particular, by learning to work with each other over time, individual employees develop a stock of human capital that is specific to co-workers and difficult to re-build with others. In the context of invention generation, Jaravel et al. (2015) show that inventors who experience an unexpected death of a co-inventor face large and long-lasting losses in earnings and productivity. Thus, strong collaborative relationships such as those established in teams of inventors imply that each individual needs complementary knowledge from other inventors to extract the maximum value of her own knowledge. This makes departure decisions more costly for the inventor and reduces her relative attractiveness to outside employers, since competitors that aim to replicate a body of knowledge must hire away the whole team (Palomeras and Melero, 2010). Therefore, we expect the negative impact of patent grants on mobility to be more intense for solo inventors than for inventors with many co-authors.

A second source of firm-specific human capital is suggested by Lazear (2009), who notes that most specific human capital is, in fact, a combination of general purpose skills applied in a combination that is specific to the firm. Innovative companies tend to establish technological trajectories linked to their core competences, with accompanying patterns of standardized routines and procedures (Nelson and Winter, 1982; Hoetker and Agarwal, 2007). This implies that the particular combination of skills used by inventors working in the company's core areas is especially idiosyncratic to the firm and, therefore, difficult to transfer. ${ }^{18}$ Thus, we expect that the negative impact of patent grants on mobility is larger for inventors working outside the firm's core technologies than for inventors employed in the firm's core.

We empirically explore the effects of the above-mentioned sources of firm-specific skills by using the following proxies: (i) the natural logarithm of (one plus) the number of unique coinventors with whom an inventor has worked in her applications up to $t$ and (ii) the percentage of her patent applications that fall in the firm's core technology areas. Following Song et al. (2003), we consider a technology area part of the core if its corresponding patent class appears with a frequency greater than $10 \%$ in the firm's application portfolio (over the entire sample period). We control in these regressions for the inventor's degree of specialization (captured by the number of different patent classes into which her applications fall) and firm size (proxied by the number of applications filed by the firm in that year), which are relevant controls to

\footnotetext{
${ }^{18}$ The firm specificity of core skills is illustrated by the following example. In 1970, Intel planned to invest in developing the first semiconductor DRAM (dynamic random access memory), the 1-kilobit 1103. Despite its economic attractiveness, Intel's engineers were seriously concerned about the potential negative consequences of developing knowledge and skills specific to DRAM technology. As noted by Gordon Moore, then CEO of Intel, "[t]here was a lot of resistance to semiconductor technology on the part of the core memory engineers. The engineers didn't embrace the 1103 until they realized that it wouldn't make their skills irrelevant" (Cogan and Burgelman, 1989, p. 2-3).
} 
consistently estimate the effect of co-inventors and core areas.

Table 4 presents the results of the interactions between sources of firm specificity and patent grants on mobility. The first column reproduces the baseline model to which we add the variables and controls mentioned in this subsection. We are interested in the interactions between the variables capturing the firm specificity of skills and the number of patents the inventor has been granted. In columns 2 and 3, we add these (instrumented) multiplicative terms separately. Column 4 shows the results for the full model. As expected, the figures from the interaction effects in columns 2 to 4 show that the negative impact of patent grants on mobility is most intense for solo inventors and for inventors working outside the firm's core technologies.

Table 4

Firm-specific human capital: patent grants, co-inventors and core technologies

\begin{tabular}{lcccc}
\hline Estimation method: 2SLS & $(1)$ & $(2)$ & $(3)$ & $(4)$ \\
Dependent variable: Move & $-0.030^{* * *}$ & $-0.072^{* * *}$ & $-0.046^{* * *}$ & $-0.075^{* * *}$ \\
& $(0.007)$ & $(0.021)$ & $(0.010)$ & $(0.021)$ \\
\# of patents issued (instr.) & & $0.021^{* * *}$ & & $0.015^{*}$ \\
& & $(0.007)$ & & $(0.008)$ \\
\# of patents issued & & & $0.041^{* *}$ & $0.035^{*}$ \\
× \# of co-inventors (L) (instr.) & & $(0.018)$ & $(0.018)$ \\
\# of patents issued & & & \\
× \% of applications in firm's core (instr.) & 0.000 & $-0.043^{* * *}$ & 0.002 & $-0.031^{*}$ \\
\# of co-inventors (L) & $(0.002)$ & $(0.016)$ & $(0.002)$ & $(0.017)$ \\
& $-0.045^{* * *}$ & $-0.044^{* * *}$ & $-0.123^{* * *}$ & $-0.112^{* * *}$ \\
\% of applications in firm's core & $(0.003)$ & $(0.003)$ & $(0.034)$ & $(0.035)$ \\
& $-0.022^{* * *}$ & $-0.017^{* * *}$ & -0.009 & -0.007 \\
\# of uspc classes (L) & $(0.004)$ & $(0.003)$ & $(0.006)$ & $(0.006)$ \\
& $-0.016^{* * *}$ & $-0.017^{* * *}$ & $-0.016^{* * *}$ & $-0.017^{* * *}$ \\
\# of applications per firm (L) & $(0.001)$ & $(0.001)$ & $(0.001)$ & $(0.001)$ \\
\hline
\end{tabular}

$N=131,485$. Number of inventors: 69,136 . Number of firms: 2,883. Estimation period is 2001-2011. Robust standard errors are clustered by inventor (in parentheses). All regressions control for the number of years since inventor's first decision (log), fixed effects for the number of applications filed by the inventor, the technology field and the year of inventor's first decision. ${ }^{*} p<0.10,{ }^{* *} p<0.05,{ }^{* * *} p<0.01$.

We also consider the role of non-compete contracts as a related mechanism that increases the firm specificity of inventors' human capital. Non-competes are contractual clauses included in labor contracts that explicitly prevent employees from working for a competitor within a certain time window, typically two years, in case of termination of the labor relationship with the current employer. These covenants are a particular case of trade secret law, which aims to safeguard critical information (both technical and non-technical) that firms decide to keep secret. Non-compete contracts are prevalent among $R \& D$ workers and have been found to reduce inventor mobility in states that enforce them (Marx et al., 2009). U.S. jurisdictions, however, differ in their degree of enforcement of these covenants. Courts have sometimes understood that employees cannot be forbidden to seek jobs in the industry in which they have expertise. In California, for instance, non-competes are practically unenforceable (Gilson, 1999). Thus, the substitutability argument suggests that patents should discourage mobility, especially in states in which non-compete covenants are not enforced.

To examine whether our results differ according to the level of enforcement of non-competes in the corresponding state, we rely on the enforceability index compiled by Starr (2016). We use the inventor address provided in patent filing for the geographical allocation of inventors to U.S. states. Because this information is not available for all inventors in our dataset, we examine a sub-sample of 25,439 inventors from 1,511 firms. 
Table 5

Firm-specific human capital: patent grants and non-compete enforceability

\begin{tabular}{|c|c|c|c|c|c|c|c|}
\hline $\begin{array}{l}\text { Estimation method: 2SLS } \\
\text { Sample } \\
\text { Dependent variable: Move }\end{array}$ & $\begin{array}{l}\text { All } \\
(1)\end{array}$ & $\begin{array}{l}\text { All } \\
(2)\end{array}$ & $\begin{array}{l}\text { All } \\
(3)\end{array}$ & $\begin{array}{l}\text { All } \\
(4)\end{array}$ & $\begin{array}{l}\text { Non-enforcing } \\
\text { states } \\
(5)\end{array}$ & $\begin{array}{l}\text { Enforcing } \\
\text { states } \\
(6)\end{array}$ & $\begin{array}{l}\text { All } \\
(7)\end{array}$ \\
\hline \# of patents issued (instr.) & $\begin{array}{c}-0.034^{* * *} \\
(0.011)\end{array}$ & $\begin{array}{c}-0.034^{* * *} \\
(0.011)\end{array}$ & $\begin{array}{c}-0.034^{* *} \\
(0.015)\end{array}$ & $\begin{array}{c}-0.034^{* *} \\
(0.015)\end{array}$ & $\begin{array}{c}-0.045^{* *} \\
(0.021)\end{array}$ & $\begin{array}{c}-0.031^{* *} \\
(0.013)\end{array}$ & $\begin{array}{c}-0.043^{* * *} \\
(0.002)\end{array}$ \\
\hline $\begin{array}{l}\# \text { of patents issued } \\
\quad \times \text { Enforceability index (instr.) }\end{array}$ & & & $\begin{array}{c}0.001 \\
(0.005)\end{array}$ & $\begin{array}{c}0.002 \\
(0.005)\end{array}$ & & & \\
\hline Enforceability index & & $\begin{array}{c}-0.009^{* * *} \\
(0.003)\end{array}$ & $\begin{array}{l}-0.010 \\
(0.013)\end{array}$ & & & & \\
\hline $\begin{array}{l}\text { \# of patents issued } \\
\quad \times \text { Enforcing states (instr.) }\end{array}$ & & & & & & & $\begin{array}{c}0.011 \\
(0.014)\end{array}$ \\
\hline Enforcing states & & & & & & & $\begin{array}{c}-0.072^{* *} \\
(0.036)\end{array}$ \\
\hline State FE & & & & Yes*** & & & \\
\hline$N$ & 47,611 & 47,611 & 47,611 & 47,611 & 10,031 & 37,580 & 47,611 \\
\hline \# of inventors & 25,439 & 25,439 & 25,439 & 25,439 & 5,480 & 20,152 & 25,439 \\
\hline \# of firms & 1,511 & 1,511 & 1,511 & 1,511 & 635 & 1,183 & 1,511 \\
\hline
\end{tabular}

Estimation period is 2001-2011. Robust standard errors are clustered at the state level (in parentheses). All regressions control for the number of years since inventor's first decision (log), fixed effects for the number of applications filed by the inventor, the technology field and the year of inventor's first decision. Enforceability scores for each state are from Starr (2016). Non-enforcing states are California and North Dakota. Since non-competes are enforceable in the state where the employee is located, we use information on inventor's location from the last patent application prior to observing the outcome. Since this information is not available for all inventors, the number of observations is lower in this analysis. ${ }^{*} p<0.10,{ }^{* *} p<0.05,{ }^{* * *} p<0.01$.

In column 1 of Table 5, we re-estimate Eq. (1) on this sub-sample. The coefficient on \# of patents issued is -0.034 and significant at the $1 \%$ level. In column 2 , we add the enforceability index, and we observe that mobility rates decline with the strength of non-compete enforcement, as in Marx et al. (2009). In columns 3 through 7, we then re-estimate the effect of patent grants on mobility by including their interaction term (and state-level fixed effects) and splitting the sample into clearly non-enforcing states (i.e., California and North Dakota) and the rest. Though the estimated effect of patenting on mobility is smaller for enforcing states than for non-enforcing ones, the difference (as captured by the interaction terms) is not statistically significant.

In sum, the evidence presented in this section regarding the relationship between patent rights and other sources of firm-specific human capital is not conclusive. While patent protection has the strongest effect as a retention mechanism for inventors without many co-authors and inventors outside the technological core of the company, we do not observe a similar substitutability pattern between patents and non-compete contracts.

\subsection{Similarity between hiring and focal firms}

Our last test of heterogeneous effects concerns different types of inter-firm moves. The complementarity of patent rights with the human capital of the corresponding inventors is expected to affect all type of moves. However, the appropriation effect resulting from the impact of patent rights on the balance of incentives to hire or retain inventors will only be relevant for technologically similar firms capable of implementing the innovation. Thus, the negative effect of patent grants on mobility observed in this study should more intensely affect moves to alternative employers in the technological vicinity of the current employer than moves to technologically distant firms, which have little chance of implementing an inventor's innovations.

To test this prediction, we characterize inter-firm technological similarity using a measure 
that captures whether the hiring and focal firms overlap in terms of core technologies. Using the same definition of a firm's core technology area used in Section 6.2, we create a categorical variable that is set to 0 when the inventor stays at the focal firm, to 1 when she leaves and at least one of the core technology domains of the two firms is identical; and to 2 when she leaves and there is no overlap in core areas. We then estimate a multinomial logit model that allows us to capture the effect of patent grants on the relative probability of each type of move. ${ }^{19}$ Table 6 shows the relative risk ratios that result from the analysis. As the first two columns show, one additional patent issued reduces the relative risk that an inventor moves to both technologically overlapping and non-overlapping employers with respect to the omitted "stay" option (both relative risks are multiplied by a factor smaller than one after a patent grant). This is consistent with the complementarity effect of patents on inventor mobility, which drives down the probability of all types of moves. A comparison of the size of the estimated ratios suggests, as predicted, that the effect is more intense for moves to employers with overlapping core technologies than for all other employers. The last column of Table 6 shows the relative risk ratios corresponding to the choice between the two types of moves, with moving to employers with no core technological overlap as the reference category. As expected, the figures indicate that an additional patent grant significantly decreases the relative risk that a moving inventor switches to a technologically similar employer instead of switching to an unrelated one. ${ }^{20}$ This is consistent with the existence of an appropriation effect that concerns exclusively technologically close employers.

Table 6

Technological core of the hiring firm and the inventor's previous firm

\begin{tabular}{lccc}
\hline & Core & Non-core & Core \\
& Move & Move & Versus \\
& Versus & Versus & Non-core \\
Dependent variable & Stay & Stay & Move \\
Estimation method: Multinomial Logit & $(1)$ & $(2)$ & $(3)$ \\
\hline \# of patents issued (instr.) & $0.694^{* * *}$ & $0.849^{* * *}$ & $0.816^{* *}$ \\
\hline
\end{tabular}

$N=131,485$. Number of inventors: 69,136. Number of firms: 2,883 . Estimation period is 2001-2011. Robust standard errors are clustered by inventor (in parentheses). All regressions control for the number of years since inventor's first decision (log), fixed effects for the number of applications filed by the inventor, the technology field and the year of inventor's first decision. Coefficients are expressed in terms of relative risk ratios. ${ }^{*} p<0.10,{ }^{* *} p<0.05,{ }^{* * *} p<0.01$.

\section{Discussion and conclusion}

In this study we investigate the effect of patent protection on the mobility prospects of inventors. We argue that, by making inventors' knowledge more specific to their current employers, patent grants decrease inter-firm mobility.

In order to test this idea, we examine the impact of obtaining a patent on the mobility

\footnotetext{
${ }^{19}$ Again, we used the control function approach proposed by Blundell and Powell (2004) and Wooldridge (2014) to correct for the endogeneity of issued patents with the average examiner leniency instrument in the multinomial logit model.

${ }^{20}$ In unreported extensions, we distinguish between a hiring firm whose core technology overlaps with the mobile inventor's own technological expertise (instead of her previous employer's core technology) to categorize moves. Replicating the specification of Table 6 for the alternative categorization produces similar results to those presented here.
} 
patterns of the inventors involved in applications. Since inventions that result in granted and not granted patents are expected to be inherently different, we adopt an instrumental variables approach to estimate the effect of patenting on inventors' mobility. In particular, and following previous literature, we use variations in the granting rates of patent examiners within an art unit (leniency) as an exogenous source of variation in patent grants. We analyze the early careers of employee inventors who apply for patents in the USPTO for the first time between 2001 and 2012. Our results indicate that patenting does cause a substantial decrease in the mobility of inventors in their early careers, suggesting that patent grants make human capital more specific to the inventor's current employer. Additional evidence provides further support for this hypothesis: (i) the negative effect of patents on mobility is particularly strong in discrete technologies, where patent protection is more effective, (ii) patents have a less negative effect on mobility when other sources of firm specificity are present. In particular, complementarities with co-inventors and employer's assets make an inventor's knowledge set more difficult to transfer outside the company, and (iii) patents make inventors especially less likely to move to technologically close alternative employers (compared to technologically distant ones). Among several other robustness tests, we extend the concept of patent protection from patent grants to the number of approved claims. The results of this analysis suggest that the appropriation effect is present over the whole population of patent applicants and not only for those producing innovations in the margin of approval and rejection.

One element of markets for inventors that our study does not address is the potential role of patents as signals of inventor ability. Previous findings in the labor economics and innovation literatures suggest that patents could reveal information about inventive skills. Patents have been frequently argued to work as signals of firm quality in situations of asymmetric information in entrepreneurial finance markets (Long, 2002; Hsu and Ziedonis, 2013; Conti et al., 2013). Analogously, patents could act as signals in the labor market for highly skilled employees, where employers are particularly likely to enjoy private information about the ability of their workers (Schönberg, 2007). By providing a signal to the labor market about the quality of the inventors responsible for the innovation, patent documents could decrease the amount of private information held by current employers and thus increase inventor mobility. Our empirical strategy, however, is based on a comparison of patent filings that have been granted and those that have not. Since the immense majority of filings are public, we would expect signaling effects to be mainly associated to patent application events and not to grant events. Indeed, it is at the time of the publication of the application when the information about the innovation and its inventors is released to the market. Thus, it is conceivable that the negative effect of patent grants on inventor mobility is preceded by a positive effect of applications due to signaling effects.

Notwithstanding the previous caveat, the evidence presented in this paper indicates that patent protection makes the human capital of inventors more firm specific and, therefore, lowers the likelihood of moving. This result has important public policy implications. First, it suggests that patents, despite making public some codified knowledge, may have a growth-reducing effect by hampering the diffusion of tacit know-how. By inducing lower mobility rates, they may reduce the spread of non-codified knowledge associated with the protected technology and, more generally, of other know-how not related to the replicability of a specific innovation. Fur- 
thermore, this appropriation-induced reduction in mobility may also contribute to an inefficient allocation of inventor's skills. Evidence from Hoisl (2007) shows that inventors tend to experience productivity increases when they switch firms, suggesting that career moves are frequently motivated by employer-employee match improvements. To the extent that patents discourage mobility, they will also inhibit these efficiency improvements. Aditionally, our results also suggest that patents generate a shift in incentives to invest in human capital from the employees (i.e., the inventors) to their employers (i.e., the patent holders). This shift may encourage some efficient investments in training that might not have been otherwise carried out by the inventors themselves because of financial constraints or risk considerations.

Last but not least, our findings bring to light an important methodological issue. If patent grants affect the mobility prospects of the authors of the inventions, tracking inventors' careers through their issued patents (as most studies have done until now) introduces a downward bias in the detection of mobility. This bias may expand to analyses of causes and consequences of mobility as well. To avoid it, further studies at the inventor level should take into account both patent applications and grants. 


\section{References}

Agarwal, R., M. Ganco, and R. Ziedonis (2009). Reputations for toughness in patent enforcement: Implications for knowledge spillovers via inventor mobility. Strategic Management Journal 30(13), 1349-1374.

Almeida, P. and B. Kogut (1999). Localization of knowledge and the mobility of engineers in regional networks. Management Science 45(7), 905-917.

Arora, A., M. Ceccagnoli, and W. Cohen (2008). R\&D and the patent premium. International Journal of Industrial Organization 26(5), 1153-1179.

Arrow, K. (1962). The economic implications of learning by doing. The Review of Economic Studies 29(3), $155-173$.

Balsmeier, B., A. Chavosh, G.-C. Li, G. Fierro, K. Johnson, A. Kaulagi, D. O'Reagan, B. Yeh, and L. Fleming (2015). Automated disambiguation of U.S. patent grants and applications. Unpublished working paper, Fung Institute for Engineering Leadership.

Becker, G. (1962). Investment in human capital: A theoretical analysis. Journal of Political Economy 70(5), $9-49$.

Blundell, R. and J. Powell (2004). Endogeneity in semiparametric binary response models. The Review of Economic Studies 71(3), 655-679.

Boldrin, M. and D. Levine (2013). The case against patents. The Journal of Economic Perspectives 27(1), 3-22.

Budd, C., C. Harris, and J. Vickers (1993). A model of the evolution of duopoly: Does the asymmetry between firms tend to increase or decrease? The Review of Economic Studies 60(3), 543-573.

Cockburn, I., S. Kortum, and S. Stern (2003). Are all patent examiners created equal? Examiners, patent characteristics and litigation outcomes. In W. Cohen and S. Merril (Eds.), Patents in the Knowledge-Based Economy, pp. 17-53. National Academies Press.

Cogan, G. and R. Burgelman (1989). Intel corporation: The dram decision. Stanford Business School Case Study 9-BP2-56A.

Cohen, W., R. Nelson, and J. Walsh (2000). Protecting their intellectual assets: Appropriability conditions and why U.S. manufacturing firms patent (or not). NBER Working Paper No. 7552.

Conti, A., J. Thursby, and M. Thursby (2013). Patents as signals for startup financing. The Journal of Industrial Economics 61(3), 592-622.

Criscuolo, P., O. Alexy, D. Sharapov, and A. Salter (2015). Lifting the veil on patents and inventions. Academy of Management Proceedings.

Fallick, B., C. Fleischman, and J. Rebitzer (2006). Job-hopping in silicon valley: Some evidence concerning the microfoundations of a high-technology cluster. The Review of Economics and Statistics 88(3), 472-481.

Farre-Mensa, J., D. Hegde, and A. Ljungqvist (2017). What is a patent worth? Evidence from the U.S. patent lottery. NBER Working Paper No. 23268.

Federal Trade Commission (2003). To promote innovation: The proper balance of competition and patent law and policy.

Fosfuri, A., M. Motta, and T. Rønde (2001). Foreign direct investment and spillovers through workers mobility. Journal of International Economics 53(1), 205-222.

Frakes, M. and M. Wasserman (2016). Patent office cohorts. Duke Law Journal 65(8), 1601-1655.

Galasso, A. and M. Schankerman (2015). Patents and cumulative innovation: Causal evidence from the courts. The Quarterly Journal of Economics 130(1), 317-369.

Ganco, M., R. Ziedonis, and R. Agarwal (2015). More stars stay, but the brightest ones still leave: Job hopping in the shadow of patent enforcement. Strategic Management Journal 36(5), 659-685.

Gaulé, P. (2015). Patents and the success of venture-capital backed startups: Using examiner assignment to estimate causal effects. Unpublished working paper, Charles University and Economics Institute of the Academy of Sciences of the Czech Republic.

Ge, C., K.-W. Huang, and I. Png (2016). Engineer/scientist careers: Patents, online profiles, and misclassification bias. Strategic Management Journal 37(1), 232-253.

Gilson, R. J. (1999). The legal infrastructure of high technology industrial districts: Silicon valley, route 128, and covenants not to compete. New York University Law Review 74, 575.

Graham, S., A. Marco, and R. Miller (2015). The USPTO patent examination research dataset: A window on the process of patent examination. USPTO Working Paper No. 2015-4.

Guellec, D. and B. van Pottelsberghe de la Potterie (2000). Applications, grants and the value of patent. Economics Letters 69(1), 109-114.

Harhoff, D., F. Scherer, and K. Vopel (2003). Citations, family size, opposition and the value of patent rights. Research Policy 32(8), 1343-1363.

Hayes, R., P. Oyer, and S. Schaefer (2006). Coworker complementarity and the stability of top-management 
teams. Journal of Law, Economics, and Organization 22(1), 184-212.

Hegde, D. (2014). Tacit knowledge and the structure of license contracts: Evidence from the biomedical industry. Journal of Economics \&3 Management Strategy 23(3), 568-600.

Heller, M. and R. Eisenberg (1998). Can patents deter innovation? The anticommons in biomedical research. Science 280(5364), 698-701.

Hoetker, G. and R. Agarwal (2007). Death hurts, but it isn't fatal: The postexit diffusion of knowledge created by innovative companies. Academy of Management Journal 50(2), 446-467.

Hoisl, K. (2006). A study of inventors: Incentives, productivity, and mobility. Ph. D. Dissertation, University of Munich.

Hoisl, K. (2007). Tracing mobile inventors - The causality between inventor mobility and inventor productivity. Research Policy 36(5), 619-636.

Hsu, D. and R. Ziedonis (2013). Resources as dual sources of advantage: Implications for valuing entrepreneurialfirm patents. Strategic Management Journal 34(7), 761-781.

Jaravel, X., N. Petkova, and A. Bell (2015). Team-specific capital and innovation. SSRN Working Paper No. 2669060.

Kim, J. and G. Marschke (2005). Labor mobility of scientists, technological diffusion, and the firm's patenting decision. The RAND Journal of Economics 36(2), 298-317.

Lamoreaux, N. and K. Sokoloff (1999). Inventors, firms, and the market for technology in the late nineteenth and early twentieth centuries. In Learning by doing in markets, firms, and countries, pp. 19-60. University of Chicago Press.

Lanjouw, J. (1998). Patent protection in the shadow of infringement: Simulation estimations of patent value. The Review of Economic Studies 65(4), 671-710.

Lanjouw, J. and M. Schankerman (2001). Characteristics of patent litigation: A window on competition. The RAND Journal of Economics 32(1), 129-151.

Lanjouw, J. and M. Schankerman (2004). Protecting intellectual property rights: Are small firms handicapped? Journal of Law and Economics 47(1), 45-74.

Lazear, E. (2009). Firm-specific human capital: A skill-weights approach. Journal of Political Economy 117(5), 914-940.

Lemley, M. and B. Sampat (2012). Examiner characteristics and patent office outcomes. Review of Economics and Statistics 94(3), 817-827.

Levin, R., A. Klevorick, S. Nelson, Richardand Winter, R. Gilbert, and Z. Griliches (1987). Appropriating the returns from industrial research and development. Brookings Papers on Economic Activity 1987(3), 783-831.

Li, G.-C., R. Lai, A. D'Amour, D. Doolin, Y. Sun, V. Torvik, A. Yu, and L. Fleming (2014). Disambiguation and co-authorship networks of the U.S. patent inventor database (1975 - 2010). Research Policy 43(6), 941-955.

Lichtman, D. (2004). Rethinking prosecution history estoppel. The University of Chicago Law Review 71(1), 151-182.

Long, C. (2002). Patent signals. University of Chicago Law Review 69(2), 625-679.

Maliranta, M., P. Mohnen, and P. Rouvinen (2009). Is inter-firm labor mobility a channel of knowledge spillovers? evidence from a linked employer-employee panel. Industrial and Corporate Change 18(6), 1161-1191.

Mansfield, E. (1986). Patents and innovation: An empirical study. Management Science 32(2), $173-181$.

Marco, A., A. Myers, S. Graham, P. D'Agostino, and K. Apple (2015). The USPTO patent assignment dataset: Descriptions and analysis. USPTO Working Paper No. 2015-2.

Martinez, C. (2010). Insight into different types of patent families. Organisation for Economic Co-operation and Development Working Paper No. 2010/2.

Marx, M., D. Strumsky, and L. Fleming (2009). Mobility, skills, and the michigan non-compete experiment. Management Science 55(6), 875-889.

Maurseth, P. and R. Svensson (2015). Tacit knowledge and the dynamics of inventor activity. Unpublished working paper, Norwegian Business School.

Moser, P. (2011). Do patents weaken the localization of innovations? Evidence from world's fairs. The Journal of Economic History 71 (2), 363-382.

Nelson, R. and S. Winter (1982). An evolutionary theory of economic change. Harvard University Press, Cambridge, MA.

Nordhaus, W. (1969). An economic theory of technological change. The American Economic Review 59(2), 18-28.

Palomeras, N. and E. Melero (2010). Markets for inventors: Learning-by-hiring as a driver of mobility. Management Science 56(5), 881-895.

Png, I. and S. Samila (2015). Trade secrets law and mobility: Evidence from "inevitable disclosure". Unpublished working paper, National University of Singapore.

Putnam, J. (1996). The value of international patent protection. Ph. D. Dissertation, Yale University. 
Sampat, B. and H. Williams (2015). How do patents affect follow-on innovation? Evidence from the human genome. NBER Working Paper No. 21666.

Schönberg, U. (2007). Testing for asymmetric employer learning. Journal of Labor Economics 25(4), 651-691.

Singh, J. and A. Agrawal (2011). Recruiting for ideas: How firms exploit the prior inventions of new hires. Management Science 57(1), 129-150.

Song, J., P. Almeida, and G. Wu (2003). Learning-by-hiring: When is mobility more likely to facilitate inter-firm knowledge transfer? Management Science 49(4), 351-365.

Starr, E. (2016). Consider this: Training, wages, and the enforceability of covenants not to compete. SSRN Working Paper No. 2556669.

Stock, J. and M. Yogo (2005). Testing for weak instruments in linear iv regression. In D. Andrews (Ed.), Identification and Inference for Econometric Models, pp. 80-108. New York: Cambridge University Press.

Toivanen, O. and L. Väänänen (2012). Returns to inventors. Review of Economics and Statistics 94 (4), $1173-1190$.

Trajtenberg, M., G. Shiff, and R. Melamed (2006). The "Names Game:" Harnessing inventors' patent data for economic research". NBER Working Paper No. 12479.

Wooldridge, J. (2014). Quasi-maximum likelihood estimation and testing for nonlinear models with endogenous explanatory variables. Journal of Econometrics 182(1), 226-234. 


\section{Appendix for "The Effect of Patent Protection on Inventor Mobility"}

This Appendix provides additional material to the results presented in "The Effect of Patent Protection on Inventor Mobility." In Section A.1, we present evidence that supplement the picture that the assignment of applications to examiners is plausibly random. In Section A.2, we discuss and report robustness checks for the first stage estimates. In Section A.3, we report the results of the robustness tests referred in section 5.3 of the article. Descriptive statistics for variables used in this Appendix are presented in A.4.sta

\section{A.1. Investigating selection}

The details of the examination process described in Section 4.2 of the article suggest that patent applications are assigned to examiners quasi-randomly within art units. Here, we provide further evidence that our proposed instrument (at the patent level) satisfies the exclusion restriction. For this restriction to hold, examiner leniency should only be related with inventor mobility through its influence on the probability that her patent application is granted. Therefore, we aim to test whether there is any correlation between the characteristics of patent applications (at the time of filing) that can be related with the likelihood that their authors move firms and our measure of examiner leniency (at the patent level). As discussed by Lemley and Sampat (2012), the assessment of whether a certain type of inventions are assigned to examiners with a certain leniency is challenging for two reasons: (i) it is difficult to identify variables that at the time of application would capture the characteristics of the underlying invention and (ii) much of the front-page information contained in patent documents is not available for applications.

One of the most important characteristics of patent applications that can affect the probability of their inventors to move is the value of the underlying innovation, since it is correlated with the inventors' ability (Palomeras and Melero, 2010; Ganco et al., 2015). Though the most common measure to proxy for value of patented innovations (e.g. citations received) is not available at the time of application and, therefore, is not useful for our purposes, there is an alternative proxy for value that it is available at filing. This is the patent family size, i.e. the number of jurisdictions in which the application is filed. Because of the substantially higher costs of filing, one expects that applicants are more likely to seek broad international protection only if the invention is economically relevant (Putnam, 1996). Prior literature provides evidence that family size is correlated with a quality index of patents (Lanjouw and Schankerman, 2004), the likelihood that a patent will be granted (Guellec and van Pottelsberghe de la Potterie, 2000) and the economic value of patent rights (Harhoff et al., 2003). We define a patent family in terms of patent equivalents, using as our measure of family size the number of unique jurisdictions in which the focal U.S. patent application was filed at the time of application and protecting the same invention. We construct this measure using the algorithm described in Martinez (2010) on the data extracted from the Worldwide Patent Statistical Database (Patstat, April 2012 edition). We are able to recover this information for all of our patent applications filed between 2001 and 2011 provided that, by January 2012, they were made public (patent applications are 
made public after 18 months from application or at the resolution date if this happens before). The final sample results in 329,666 observations for which we have non-missing values for examiner leniency and application data. We report the results of the OLS regression of family size on examiner leniency (as described in subsection 4.2.2) in Column 1 of Table A1. We use art-unit fixed-effects in order to control for potential patterns regarding family size across technologies. We find that the key coefficient on examiner is small (0.003) and insignificant ( $p$-value $=0.877$ ), suggesting that more lenient examiners are unlikely to be systematically assigned more valuable patent applications.

Another used measure for value of (potentially) patented innovations is the number of backward references. A relatively high number of references to previous patents and non-patent literature may indicate innovations of relatively high value, although this is not entirely unambiguous (see Harhoff et al., 2003). Given the importance of cited prior art in later litigation, the idea is that an applicant who seeks to protect a more valuable invention might have incentives to delineate the patent claims by inserting more references to prior art. Note that U.S. patent law imposes a duty of candor on patent applicants to disclose to the Patent Office any information that is "material" to the issuance of the patent (see 37 C.F.R. 1.56). A failure to do so may render the resulting patent unenforceable. We use then the number of applicant-submitted references to patent and non-patent literature at the time of filing available in Patstat. This data is only available though for the subset of applications that are eventually issued as patents. Also in this case, results suggest that there is no clear evidence that more lenient examiners get assigned applications that could protect potentially more valuable innovations.

Finally, we test whether there might be selection based on applicants' size, since this may be a factor that could influence the likelihood of inventors to move. We use as a proxy for size the number of patent applications the applicant filed in the previous year. The last column of Table A1 report an insignificant coefficient on examiner leniency.

Table A1

Examiner relative leniency and application characteristics

\begin{tabular}{|c|c|c|c|c|}
\hline $\begin{array}{l}\text { Dependent variable } \\
\text { Estimation method: OLS }\end{array}$ & $\begin{array}{l}\text { Family size } \\
(1)\end{array}$ & $\begin{array}{c}\text { Applicant PAT } \\
\text { References } \\
(2)\end{array}$ & $\begin{array}{c}\text { Applicant NPL } \\
\text { References } \\
(3)\end{array}$ & $\begin{array}{c}\text { Applicant APP } \\
\text { Volume }_{t-1} \\
(4)\end{array}$ \\
\hline Examiner leniency & $\begin{array}{c}0.003 \\
(0.022)\end{array}$ & $\begin{array}{c}0.433 \\
(0.347)\end{array}$ & $\begin{array}{c}0.223 \\
(0.271)\end{array}$ & $\begin{array}{l}-37.600 \\
(26.413)\end{array}$ \\
\hline $\begin{array}{l}\text { Filing year FE } \\
\text { Art unit FE }\end{array}$ & $\begin{array}{l}\text { Yes*** } \\
\text { Yes*** }\end{array}$ & $\begin{array}{l}\text { Yes*** } \\
\text { Yes*** }\end{array}$ & $\begin{array}{l}\text { Yes*** } \\
\text { Yes*** }\end{array}$ & $\begin{array}{l}\text { Yes*** } \\
\text { Yes*** }\end{array}$ \\
\hline $\begin{array}{l}N \\
\# \text { of examiners }\end{array}$ & $\begin{array}{c}329,666 \\
9,855\end{array}$ & $\begin{array}{c}164,832 \\
7,629\end{array}$ & $\begin{array}{c}164,832 \\
7,629\end{array}$ & $\begin{array}{c}341,007 \\
9,918\end{array}$ \\
\hline
\end{tabular}

Estimation period is 2001-2011 in columns 1 to 3 and 2002-2011 in columns 4 and 5 . Robust standard errors are clustered by examiner (in parentheses). ${ }^{*} p<0.10,{ }^{* *} p<0.05$, ${ }^{* * *} p<0.01$.

\section{A.2. Robustness tests for the first stage results}

In this Appendix, we test whether our measure of examiner leniency (at the patent level) may be driven by technological effects within an art unit. Even though art units correspond to quite delimited technological areas, there may be subareas within an art unit that differ in the patentability of their applications. We can only distinguish these technological sub-areas by 
looking at the classes and subclasses to which the application is assigned to. Though art units are typically a more fine-grained classification of technologies (there are more art units than technological classes), in some cases there may co-exist different classes or, more frequently, different subclasses in an art unit (see https://www.uspto.gov/web/patents/classification). Therefore, we want to rule out that part of the variation in the measured leniency across examiners may be due to the variation in grant rates across technological (sub)classes within an art unit. This issue is particularly important because we do not conduct our analysis at the patent level but at the inventor level (i.e., we aggregate our relative leniency measure over the applications filed by a given inventor up to a given moment of time), and therefore we cannot include (sub)class fixed-effects in our empirical specifications. We explore whether the aforementioned technological effects may be a concern for our measure of examiner leniency by testing whether the correlation between examiner leniency and patent grant varies substantially when we include more fine-grained technological controls. Table A2 contains the results from this robustness test. Column 1 contains the baseline correlation between examiner leniency and patent grant without introducing any technological control. Note that our examiner leniency measure is constructed relative to the art unit and year [see Eq. (2) and (4) of the paper]. This is why we obtain a very similar coefficient when we introduce fixed effects by art unit and year (column 2). Column 3 introduces art unit, year and class fixed effects, in order to control for the effects of classes that either expand over different art units or that share the art unit with another class. Next, we control for the most stringent fixed effects, at the art-unit, year and sub-class level (note that sub-classes are nested in classes). Across all these more stringent specifications, the correlation of examiner leniency and patent grant does not present substantial variations with respect to the baseline model, suggesting that our leniency measure is not the result of differences in the patentability across technological areas inside an art unit.

Table A2

Technology classification, examiner leniency and patent grants

\begin{tabular}{|c|c|c|c|c|}
\hline \multicolumn{5}{|l|}{ Dependent variable: Patent grant } \\
\hline $\begin{array}{l}\text { Technology FE included } \\
\text { Estimation method: OLS }\end{array}$ & $\begin{array}{c}\text { None } \\
(1)\end{array}$ & $\begin{array}{l}\text { Art unit } \times \\
\text { Filing year } \\
\quad(2)\end{array}$ & $\begin{array}{l}\text { Art unit } \times \\
\text { USPC class } \times \\
\text { Filing year } \\
\text { (3) }\end{array}$ & $\begin{array}{l}\text { Art unit } \times \\
\text { Sub-class } \times \\
\text { Filing year } \\
\quad(4)\end{array}$ \\
\hline Examiner leniency & $\begin{array}{c}0.737^{* * *} \\
(0.008) \\
\end{array}$ & $\begin{array}{c}0.736^{* * *} \\
(0.006) \\
\end{array}$ & $\begin{array}{c}0.720^{* * *} \\
(0.006) \\
\end{array}$ & $\begin{array}{c}0.741^{* * *} \\
(0.011) \\
\end{array}$ \\
\hline $\begin{array}{l}N=353,976 . \text { Number of exam } \\
\text { JSPC classes: } 413 \text {. Number of } \\
\text { Robust standard errors are clus } \\
<0.05,{ }^{* * *} p<0.01 .\end{array}$ & $\begin{array}{l}\text { ers: } 10,1 \\
\text { b-classes } \\
\text { red by e }\end{array}$ & $\begin{array}{l}\text { 2. Number } \\
\text { 41,898. E } \\
\text { aminer (in }\end{array}$ & $\begin{array}{l}\text { art-units: } 62 \\
\text { nation period } \\
\text { rentheses). }\end{array}$ & $\begin{array}{l}\text { Number o } \\
\text { is } 2001-2011 \\
p<0.10 \text {, }^{*}\end{array}$ \\
\hline
\end{tabular}

\section{A.3. Other robustness tests}

In this section, we present additional regression results corresponding to the robustness tests referred in Section 5.3 of the article. 
Table A3

Patent grants and inventor mobility-Miscellaneous robustness tests

\begin{tabular}{|c|c|c|c|c|c|c|}
\hline $\begin{array}{l}\text { Estimation method: } 2 \text { SLS } \\
\text { Sample } \\
\text { Dependent variable: Move }\end{array}$ & $\begin{array}{l}\text { All } \\
(1) \\
\end{array}$ & $\begin{array}{l}1^{\text {st }} \text { dec. } \\
\text { up to } 2006 \\
(2)\end{array}$ & $\begin{array}{c}\text { Active } \\
\text { firms } \\
(3) \\
\end{array}$ & $\begin{array}{l}\text { All } \\
(4)\end{array}$ & $\begin{array}{l}\text { All } \\
(5) \\
\end{array}$ & $\begin{array}{l}\text { All } \\
(6) \\
\end{array}$ \\
\hline \# of patents issued (instr.) & $\begin{array}{c}-0.028^{* * *} \\
(0.006)\end{array}$ & $\begin{array}{c}-0.021^{* * *} \\
(0.008)\end{array}$ & $\begin{array}{c}-0.029^{* * *} \\
(0.006)\end{array}$ & $\begin{array}{c}-0.044^{* *} \\
(0.019)\end{array}$ & $\begin{array}{c}-0.028^{* * *} \\
(0.006)\end{array}$ & $\begin{array}{c}-0.026^{* * *} \\
(0.008)\end{array}$ \\
\hline $\begin{array}{l}\text { \# of patents issued } \\
\quad \times \# \text { of patents issued (instr.) }\end{array}$ & & & & $\begin{array}{c}0.002 \\
(0.002)\end{array}$ & & \\
\hline Litigiousness & & & & & $\begin{array}{c}-0.001^{* *} \\
(0.001)\end{array}$ & $\begin{array}{c}0.008 \\
(0.019)\end{array}$ \\
\hline $\begin{array}{l}\text { \# of patents issued } \\
\quad \times \text { Litigiousness (instr.) }\end{array}$ & & & & & & $\begin{array}{l}-0.003 \\
(0.007)\end{array}$ \\
\hline Refined (2-digit) Tech class FE & Yes*** & & & & & \\
\hline$N$ & 131,485 & 69,069 & 130,082 & 131,485 & 131,485 & 131485 \\
\hline \# of inventors & 69,136 & 36,403 & 68,065 & 69,136 & 69,136 & 69,136 \\
\hline \# of firms & 2,883 & 2,115 & 2,471 & 2,883 & 2,883 & 2,883 \\
\hline
\end{tabular}

Robust standard errors are clustered by inventor (in parentheses). All regressions control for the number of years passed since inventor's first decision (log), and fixed effects for the number of applications filed by the inventor and the year of inventor's first decision. Technology field fixed effects use six categories in columns 2 through 6 , and 37 sub-categories in column 1. Litigiousness is defined as the moving sum of the number of unique patent infringement lawsuits initiated by the source firm from year $t-1$ to year $t-3$ (see Ganco et al., 2015). ${ }^{*} p<0.10,{ }^{* *} p<0.05,{ }^{* * *} p<0.01$.

Table A4

Claims and inventor mobility

\begin{tabular}{|c|c|c|c|c|c|c|}
\hline Sample & All & All & All & Patents & Patents & Patents \\
\hline Estimation method & OLS & $\begin{array}{c}\text { OLS } \\
\left(1^{\text {st }} \text { st. }\right)\end{array}$ & $\begin{array}{c}\text { 2SLS } \\
\text { (2nd } \text { st.) }\end{array}$ & OLS & $\begin{array}{c}\text { OLS } \\
\left(1^{\text {st }} \text { st. }\right)\end{array}$ & $\begin{array}{c}2 \text { SLS } \\
\left(2^{\text {nd }} \text { st. }\right)\end{array}$ \\
\hline Dependent variable & $\begin{array}{l}\text { Move } \\
(1)\end{array}$ & $\begin{array}{l}\text { Avg. \# of } \\
\text { claims iss. } \\
(2)\end{array}$ & $\begin{array}{l}\text { Move } \\
(3)\end{array}$ & $\begin{array}{l}\text { Move } \\
\text { (4) }\end{array}$ & $\begin{array}{l}\text { Avg. \# of } \\
\text { claims iss. } \\
(5)\end{array}$ & $\begin{array}{l}\text { Move } \\
(6)\end{array}$ \\
\hline Avg. \# of claims issued & $\begin{array}{c}-0.001^{* * *} \\
(0.000)\end{array}$ & & & $\begin{array}{c}0.000 \\
(0.000)\end{array}$ & & \\
\hline Examiner lenciency & & $\begin{array}{c}18.075^{* * *} \\
(0.355)\end{array}$ & & & $\begin{array}{c}12.415^{* * *} \\
(0.426)\end{array}$ & \\
\hline Avg. \# of claims issued (instr.) & & & $\begin{array}{c}-0.003^{* * *} \\
(0.001)\end{array}$ & & & $\begin{array}{c}-0.002^{* *} \\
(0.001)\end{array}$ \\
\hline First-stage $F$-statistic & & 2,721 & & & 566 & \\
\hline
\end{tabular}

$N=131,485$ (111,921 in column 4-6). Number of inventors: 69,136 (57,926 in column 4-6). Number of firms: 2,883 (2,567 in column 4-6). Estimation period is 2001-2011. Robust standard errors are clustered by inventor (in parentheses). All regressions control for the number of years passed since inventor's first decision ( $\log$ ), and fixed effects for the number of applications filed by the inventor and the year of inventor's first decision. ${ }^{*} p<0.10,{ }^{* *} p<0.05,{ }^{* * *} p<0.01$.

\section{A.4. Descriptive statistics of appendix variables}

Table A5

Descriptive statistics (Robustness tests)

\begin{tabular}{lcccccc}
\hline Variable & Mean & SD & Min & Median & Max & Observations \\
\hline \multicolumn{2}{l}{ Application-level characteristics } & & & & & \\
Family size & 1.5 & 1.7 & 0 & 1 & 27 & 329,666 \\
Applicant PAT references & 4.3 & 13.4 & 0 & 0 & 105 & 164,832 \\
Applicant NPL references & 1.5 & 8.2 & 0 & 0 & 99 & 164,832 \\
Applicant APP volume $t-1$ & 1,261 & 1,840 & 0 & 427 & 7,803 & 341,007 \\
& & & & & & \\
Inventor-level characteristics & & & & & & \\
Litigiousness & 0.79 & 1.5 & 0 & 0 & 10 & 131,485 \\
Avg. \# of claims issued & 12.6 & 8.9 & 0 & 11.5 & 248 & 131,485 \\
\hline
\end{tabular}

